\title{
Practice and Exploration of School Emergency Injury Education System
}

\author{
Lihong Dong \\ Shang Hai Second Polytechnic University \\ Pu Dong New Area, Shang Hai, China
}

\author{
Lin Tian \\ Shang Hai Jian Qiao University \\ Pu Dong New Area, Shang Hai, China
}

\begin{abstract}
In the view of school education system, how to solve and deal with all kinds of emergency injury incidents inside and outside the school, students' understanding is still in the "blind spot" situation. This paper discusses the advantages of emergency injury education and ability training into the school physical education curriculum system. It points out the randomness and temporary nature of school emergency injury education in our country. Research considers, realizing the lifelong education of the students' emergency injury education and ability training, it is the key to bring them into the school physical education curriculum system.
\end{abstract}

Keywords-School; Emergency injury accident; Education system; practice

\section{INTRODUCTION}

In the field of school education, students constitute the main body of campus life. From most of the domestic campus architecture and the total number of students, the school is a place with a high degree of population density. This density is more likely to be in a state of chaos and disorder when dealing with a variety of sudden disasters and risks. Therefore, disasters such as campus disasters caused by the Wen Chuan earthquake and other forms of campus emergencies will lead to significant loss of life and property. It also highlights the importance and urgency of education for students to carry out security risks. However, when we further study what factors will cause campus unexpected accidents to a great extent, the common factors behind it are students' instinctive phenomenon of emergency and self rescue measures in sudden accidents. It is obvious that this almost conditioned reflex instinct treats sudden accidents, and the effect is imaginable. In this situation, how to strengthen the emergency damage on the question of education of students, from the view of the theory of the view point of view is varied, but once into practice, due to various disasters and accidents risk characteristics of low probability, if we really want to hurt the emergency education knowledge ability training mode, until the full realization of the full range and the whole process, so far, from the induction of all kinds of documents and materials, and no curing mode successfully can follow. Based on this, the author tries to start from the current campus public safety protection dilemma, this paper explores the cultivation of students' ability of emergency injury education and physical education system in primary and middle schools, students from the school at the beginning can long-term system accept emergency education related injury knowledge and obtain a series of emergency injury skills, and optimize the current prevention and treatment of a variety of school education in the field of emergency one-sided, superficial situation, and ultimately the ability of students to emergency refuge lifelong life and property intensive.

\section{CONNOTATION OF EMERGENCY INJURY ACCIDENT EDUCATION}

In the definition of school emergency injury accident education, a more detailed interpretation is the "public safety education program for primary and secondary schools" issued by the Ministry of education in March 2007. The outline mainly includes four aspects: 1) the guiding ideology and objectives of public safety education. 2) the main content. 3) the way to implement it. 4) guarantee mechanism. As in guiding ideas, goals and main contents, the "Outline" clearly pointed out that the public safety of primary and secondary education mainly include prevention and response to social security incidents or events, public health accidents, accidents, natural disasters and network information security incidents and other content, and in accordance with the cognitive characteristics of students of different ages, the detailed provisions of the school of public security education content; in the implementation of the "Outline", requires all schools to penetrate the public safety education content in the teaching and the comprehensive practice course, and the class, group, school, flag raising ceremony, seminars, poster, visit and other forms of exercise, help students master the knowledge system of public security, through the game, simulation and experience is the theme of teaching activities, enhance public safety education effect; in the security system, the "Outline" also requires schools and Public Security、The Departments of Fire、Transportation and Health should establish close ties, invite relevant personnel to serve as off campus counselors, assist schools in developing emergency evacuation plans and organize evacuation exercises. ${ }^{[1]}$

By analyzing the above outline, although the outline from the content and form of clearly defined public safety aspects of education, but in the specific implementation measures, the outline is not able to provide systematic training of students injury accident emergency education and the ability of the program, and present "sporadic" characteristics. It is only in the form of various activities to help students enhance the effect of public safety education. In addition, there is not a clear definition of how to deal with unexpected incidents and 
avoid injury at present. Therefore, in the study of emergency and injury, respectively, education three lexical interpretation, also through the comprehensive construction, the author considers that the emergency accident refers to the education in the state of emergency in order to avoid accidents or mitigate the consequences of the accident and take actions beyond the normal working procedures. The comprehensive classification of emergency injury accident education includes four main factors: 1) knowledge of emergency injury accident. 2) emergency injury accident technology. 3) psychological training of emergency injury. 4) physical culture of emergency injury.

\section{ANALYSIS OF THE ADVANTAGES OF EMERGENCY INJURY ACCIDENT EDUCATION INTO THE SCHOOL PHYSICAL EDUCATION CURRICULUM SYSTEM}

A. The education of emergency injury accidents is brought into the advantages of the long effect mechanism of physical education curriculum system

In our country's school physical education curriculum system, sports is an important compulsory course. Among them, in the nine year compulsory education, there are 4 physical education classes per week in grade 1-2, and 3 sports classes per week in grade 3-9. The senior middle school and the University have 2 sports classes a week. According to the distribution of school sports class, if students' injury accidents emergency education and ability training in college physical education system, one can effectively link the students from primary school to university during the period of emergency accident education and ability training concept, do the whole process of training emergency accident education and the ability of the students from the beginning of training students to accept the system of emergency accidents and ability of knowledge education. On the other hand, physical education is a compulsory course for students, which fully ensures every student's participation in the education of emergency injuries and the training of their abilities. And this kind of whole staff can effectively prevent schools from training exercises, students' passive participation in the "Pepper Noodle" phenomenon, covering and improving students' ability of emergency escape. Thus it is beneficial to the formation of the long-term mechanism of the education and ability training for the emergency injury accidents of the students.

\section{B. Analysis on the advantages of school physical education teachers}

School physical education is generally composed of primary school sports, middle school sports and university sports. In terms of the configuration of the school physical education teachers, most of the school physical education courses are taught by the physical education teachers. Through further inquiries detailed research data found that more than $80 \%$ of the school physical education teachers graduated from major sports college or department. And before graduation, more than 93\% of PE Teachers' physical education courses contain a series of life-saving knowledge, such as sports lifesaving, sports health care, sports physiology and sports anatomy. Besides, in addition to the theoretical knowledge of sports courses related to this kind, more than $96 \%$ of the physical education teachers should practice the sports and tactics repeatedly during the period of school. After deconstructing part of sports skills and tactics, it is not difficult to find that there is a great correlation between sports skills and tactics and the training of emergency injury practical ability. For example, the majority of full-time sports college students to systematically study the gymnastics curriculum, and Before The Roll Gymnastics course in technology, if be designed to selectively "copy" to the fire escape skills to the fire escape process, because the smoke and fire will diffuse quickly blocking escape away the opportunity kind of circumstance, the trapped persons tend to choose the lower floors and jumped to escape, jumped to escape a position if the master Before The Roll buffer intensity, will greatly reduce the trapped injured degree. This fully illustrates that the school physical education teachers have a better knowledge of the theoretical and practical knowledge of the education and ability training for the students in emergency injury accidents. Thus, it has improved the past sporadic emergency injury accident education model. For example, most of the current school students injury accident emergency education is the main mode of organizing and guiding the exercise of the sporadic school security branch, counselor, teacher, geography or common sense class teacher guidance, individual or even hire outside experts to carry out seminars and other students should pay the damage emergency education, accident emergency education and this kind of lecture in nature and not let students get a comprehensive system of sustainable development, which is disadvantageous to the students injury accident emergency education .

\section{The function of the school physical education curriculum is helpful to promote the prevention level of the students' emergency injury ability}

Sports education and exercise give students the double income of physical and mental health. This is because the physical education curriculum has its own unique fitness, healthy heart function. Through the study of sports programs, students can improve their physical function on the one hand, so that students can have better physical ability to cope with danger. On the other hand, but also can improve the students' psychological ability, in order to make students more calm to deal with emergency injury crisis. What is worth mentioning here is that this enhanced physical and mental health will also help to form and develop emergency risk avoidance capabilities, and improve students' preventive skills for emergency injury accidents. An experiment of this conclusion in early 2004 by Fan Xue Feng on hundreds of experienced personnel in the accident investigation danger has been effectively confirmed, the study found that compared with no regular exercise and no sports expertise of personnel engaged in sports training and often participate in physical exercise, the probability of injury is small, only $14 \%$ of ${ }^{[2]}$, in addition, from the statistical data in this group of key elements in anatomy are that this interaction is realized mainly through the following ways: 1) emergency sports itself has. There are many similarities and similarities between sports technology and emergency injury prevention technology. For example, The Roll Technology Gymnastics Diving, Swimming in the rescue and rescue methods. 2) the conditioning function can be provided better. In sports, if it is often engaged in physical 
exercise, it can be better to produce action stereotypes. This type of stereotype, in turn, provides a possibility for better accident prevention.

\section{THE IDEA OF INTEGRATING EMERGENCY INJURY EDUCATION INTO THE SCHOOL PHYSICAL EDUCATION CURRICULUM SYSTEM}

From 571 BC to 471 BC, the greatest philosopher and thinker of our country, Lao ZI, had put forward the theory of "Fu Xi and Misfortune". The theory reveals the importance of peace. But in reality, there is still a big "blind area" for students to understand and deal with emergency emergencies. It does not even have the related emergency injury prevention ability. Therefore, in Si Chuan by the Wen Chuan earthquake warnings and other domestic serious campus emergencies the consequences of the disaster lash, the author tentatively students injury accident emergency education into the curriculum system of school physical education, so that students fully combined with the characteristics of school physical exercise, continue to strengthen their own emergency rescue ability and damage. Strengthen emergency ability..

\section{A. Specific content of emergency injury accident Education}

Before bringing the emergency injury education into the sports curriculum system, it is necessary to define clearly the specific content of the emergency injury education. As mentioned earlier, the education of emergency injury accidents in universities, middle schools and primary schools covers four major elements. But when it comes to the specific training contents of emergency injury accidents, this article is mainly based on Xia Xiao Lin's research view, which is classified as public transportation, public facilities, natural disasters, public health, social security and psychological adaptation. Here, public transportation and public facilities to emergency measures for students to go out by car, train, subway stop, the aircraft burning and explosion disaster; natural disasters are irresistible natural disasters when students encounter risk culture; public health refers to the control method and the students' physical disease, food poisoning and other health and safety the problem; social security mainly refers to the students involved in the riots, safety related violence, terrorist attacks; psychological adaptation is to cultivate students' response to the disaster the psychological setback. ${ }^{[3]}$

\section{B. The idea of emergency injury accident education into the school physical education classroom teaching}

The awareness and ability of students' emergency injury prevention will not be achieved overnight, and it is necessary to start and educate them when they are small. The sustainable development of this kind of training mechanism can be guaranteed in the teaching of physical education. This kind of guarantee is caused by the unique function of the physical education course itself. Therefore, the education of emergency injury accident should be brought into the teaching of physical education, and the content of application can be excavated more. First of all, physical education teachers should deeply analyze the implicit sports life-saving knowledge in physical education teaching contents, and develop students' emergency injury prevention ability education timely and according to local conditions. For example, in the teaching form, such as dance and yoga, physical education teachers can make full use of teaching equipment, from high jump to the sponge pad so that students have the awareness of the practice, after wrestling roll buffer. For example, physical education teachers can use the opportunity to swim in the swimming pool and carry out the ability to save and save the students. Secondly, the emergency accidents in education and sports teaching facilities can be shared more, this greatly reduces the specific students injury accidents emergency ability and investment, but also conducive to the "emergency damage ability" of rapid development in the country in the middle and primary school.

\section{The idea of the education of emergency injury accident into the extracurricular physical exercise of the school}

In the field of school physical education, students' extracurricular physical exercise is an extension of physical education classroom teaching, which is complementary to school physical education. It is an important way to achieve school sports goals and quality education, and is also an important form of school sports. It mainly includes the early exercise of the students and the afterschool physical exercises in the afternoon. Therefore, the way to carry out emergency injury accident education in students' extracurricular sports activities can be divided into two categories: First, we should make full use of afternoon extracurricular physical exercise for lectures on emergency injury accidents, such as instructing firefighters and physical education teachers to give lectures on fire knowledge and life-saving knowledge. In addition, students regularly organize various relevant forms and knowledge contest activities, such as sports element into the emergency accident, organized education exhibition, poster etc. This kind of emergency injury accident education carried out by afternoon extracurricular physical exercise is mainly to deepen the popularization of knowledge about emergency injury prevention ability in theory, and lay the foundation for students' next personal practice. Two, with the help of the characteristics of student group early exercise, we should effectively combine students' emergency injury ability training with students' early exercise, carry out large-scale emergency evacuation simulation exercise training regularly and regularly. For example, to change the students' mass practice exercises in the playground, the students in the corridor simulation training of emergency fire self-help and mutual aid, let the students accept damage ability training, improve the ability of self-help and mutual aid. In addition, this large-scale simulation training should be conducted regularly and can be controlled flexibly in time, such as two simulated training sessions per week.

\section{Envisage of emergency injury accident education into school sports competition}

Emergency injury accident education and ability training can not only be included in daily sports classroom teaching and extracurricular physical exercise, but also the training of this injury ability can get more students' favor through the stage of sports competition. For example, in the annual school sports meeting, various forms of emergency escape competitions can be set up, so that students can choose their own competition equipment and spend time in spare time to improve their competitive level of emergency escape, so as to compete in the school sports meeting. On the one hand, this 
kind of competition is full of interest, and on the other hand, it further improves the monotonous tedium of the past school sports meeting and makes more students integrate into it.

\section{E. Using network blog to build a new education platform for students' emergency injury accident}

Network blog, as a new form of network communication and interaction platform, can provide students with the network stage of self expression, self management and multi communication. Through this interaction mode, we not only add a new way to students' emergency injury education, but also have more convenient and interactive features than traditional Internet communication methods, such as BBS and personal homepage. And the management of the blog is relatively simple than BBS. Therefore, in the process of education for emergency injury accidents by Internet bloggers, there are three modes: student group blog, teacher group blog and teacher student interaction group blog. The part of the teacher group blog is composed of physical education teachers, public safety experts and people who are good at all kinds of safety protection knowledge. These three modes, on the one hand, can enable teachers group to better understand the shortcomings of students' emergency injury education and guide students' related skills through dynamic network records. On the other hand, building a platform of interaction between teachers and students can effectively eliminate the limitation of time and space, and establish a truly democratic and equal communication atmosphere between teachers and students, so that students can get better initiative in acquiring knowledge of emergency injury. In addition, students can also widely use their blog to form their own resonance group, and ultimately achieve their positive interaction education mode of autonomous learning, self management, equality and participation.

\section{CONCLUSION}

Emergency injury accident education refers to action taken in an emergency to avoid the occurrence of accidents or to reduce the consequences of the accident. The comprehensive classification of it includes four main elements: 1) knowledge of emergency injury accident. 2)emergency injury accident technology. 3) psychological training of emergency injury. 4) physical culture of emergency injury.

The main factors of the education of emergency injury accidents included in the school physical education curriculum system are as follows: the education of emergency injury accidents is brought into the advantages of the long effect mechanism of the sports curriculum system; The advantages of school physical education teachers' strength; The function of the school physical education curriculum is helpful to promote the prevention level of the students' emergency injury ability.

The idea of the physical education curriculum system of the emergency injury accident education school is as follows: The specific content of emergency injury accident education; The education of emergency injury accidents is envisaged in the teaching of physical education in school; The education of emergency injury accident is envisaged for the extracurricular physical training of the school; The education of emergency injury accidents is envisaged in the school sports competition; The Internet blog is used to build a new education platform for students' emergency injury accidents.

\section{REFERENCES}

[1] Taizhou daily. China promulgated the outline of public safety education in primary and secondary schools[EB/OL]. [2011-01-18].

[2] Xue Feng Fan. Hurt education in Physical Education Teaching[J]. Innovation technology,2004(3):55

[3] Xiao Lin Xia. Emergency risk prevention education should be incorporated into China's school physical education curriculum system[J]. Social Sciences Review,2008(12):236 